\title{
A retrospective epidemiological study of skin diseases among pediatric population attending a tertiary dermatology referral center in Northern Greece
}

\section{Efstratios Vakirlis \\ Grigorios Theodosiou \\ Zoe Apalla \\ Michael Arabatzis \\ Elizabeth Lazaridou \\ Elena Sotiriou \\ Aimilios Lallas \\ Demetrios loannides}

First Department of Dermatology, Aristotle University Medical School, Thessaloniki, Greece

\author{
This article was published in the following Dove Press journal: \\ Clinical, Cosmetic and Investigational Dermatology \\ 3 April 2017 \\ Number of times this article has been viewed
}

Background: The incidence of skin diseases in children is influenced by hereditary, social, and environmental factors. The objective of this study was to determine the incidence of pediatric dermatoses at a University Hospital in Northern Greece.

Patients and methods: We reviewed epidemiologic data of 940 patients, aged 0-18 years, who were referred to the outpatient clinic of a University Hospital between January 2013 and December 2015. Demographic data and the frequency of the various diagnoses in various age groups were studied.

Results: Nine hundred and forty children and adolescents with 1020 diagnoses were included in the study (52.8\% females and $47.2 \%$ males). The 10 most frequent diagnoses were: dermatitis/eczema (31.5\%), viral infections (12.5\%), pigmentary disorders (7.4\%), melanocytic nevi $(5.8 \%)$, alopecia areata $(5.8 \%)$, acne $(5.6 \%)$, nail disorders $(3.3 \%)$, vascular malformations and hemangiomas (2.9\%), psoriasis (2.6\%), and bacterial infections (2.6\%). Atopic dermatitis was the most prevalent dermatosis in all age groups accounting for a total of $20.9 \%$ of the study population. A remarkably high incidence of various forms of mastocytosis $(2.2 \%)$ was seen in our data. Conclusion: Atopic dermatitis is the most frequent pediatric dermatosis in all age groups. Viral infections, pigmentary disorders, and nevi account for a significant proportion of the referrals. The high incidence of mastocytosis in our study may be attributed to overdiagnosis, overestimation due to the relatively small study population, or it may represent the real incidence of mastocytosis in our region. The low incidence of acne in our study may be attributed to the fact that only severe cases are referred to our hospital.

Keywords: epidemiology, pediatric dermatology, atopic dermatitis, infection-viral, mastocytosis

\section{Introduction}

Skin diseases account for a significant proportion of pediatric consultations $(6-24 \%){ }^{1-3}$ Ethnic, socioeconomic, and environmental factors influence their incidence ${ }^{4-10}$ Dermatoses in the pediatric population differ from those in adults in terms of diagnostic approach and management, while some of them manifest mainly or exclusively in children.

The increasing frequency of pediatric skin disease ${ }^{11}$ represents a substantial part of morbidity in children. However, only few data extracted from few studies are currently available about the epidemiology of pediatric dermatoses. ${ }^{2-6,9-18}$

The aim of this study was to estimate the incidence rates of pediatric skin diseases in our region that can subsequently serve as reference material for future comparative studies
Correspondence: Grigorios Theodosiou First Department of Dermatology Venereology, Aristotle University Medical School, I 24 Delfon street, 52440, Thessaloniki, Greece Email Grigorios.Theodosiou@skane.se 


\section{Patients and methods}

We reviewed the records of all patients aged $0-18$ years, who were examined at the pediatric dermatology clinic of the First Department of Dermatology of the Aristotle University Medical School in Thessaloniki, Greece, during the period January 2013 - December 2015.

Epidemiologic data (age, sex, nationality), family and personal history, and diagnosis were extracted from the patient's medical records. Patients with missing information were excluded from the study. The diagnoses reported on the medical records were based on clinical features and were confirmed by laboratory tests or skin biopsy, when indicated.

Patients were grouped according to sex and age group as follows: newborns and infants ( $<12$ months), toddlers and preschoolers ( $1-5$ years), scholars (6-12 years), and teenagers ( $>12-18$ years).

This is a single-center, chart review study, which has been approved by Aristotle University Ethics Committee, and conducted in accordance with the latest version of the Declaration of Helsinki. Trial registration number is $3 \mathrm{~b} / 11.09 .2015$. The need for informed consent was waived by the Institutional Review Board as the trial is non-interventional and the patients' data provided are sufficiently anonymized. The guardians of the children provided written informed consent for publication of photos used.

\section{Results}

Between January 2013 and December 2015, 1080 children were examined for the first time in our department. Nine hundred and forty children with 1020 diagnoses, 444 boys (47.2\%) and 496 girls (52.8\%), were included in the study. Eighty patients were diagnosed with more than 1 skin disease. One hundred and forty patients were excluded from the analysis due to insufficient data reported in their medical history.

According to age group, we examined 102 newborns and infants, 374 preschoolers, 366 scholars, and 98 teenagers. Distribution of various dermatoses in the study population in descending frequency is presented in Table 1.

The most common type of dermatosis found in our study was dermatitis/eczema, constituting a total of $31.5 \%$ of the study population. Atopic dermatitis (AD) was clearly the most common diagnosis of all age groups affecting $20.9 \%$ of all patients (63.7\% of the dermatitis group). Seborrheic dermatitis (cradle cap) accounted for $9.9 \%$ of the dermatitis diagnoses, being the second most frequent dermatitis in newborns and infants. Other subtypes of dermatitis were pityriasis alba (7.8\%), contact dermatitis (7.5\%), and diaper dermatitis (3.7\%), which predominantly affects girls (75\%) between 0 and 5 years, nummular eczema (3.7\%), dyshidrotic
Table I Skin diseases in the study population between January 2013 and December 2015 in Thessaloniki, Greece

\begin{tabular}{lll}
\hline Skin disease & $\mathbf{n}$ & $\%$ \\
\hline Dermatitis / eczema & 322 & 31.5 \\
Viral infection & 127 & 12.5 \\
Pigment disorders & 74 & 7.3 \\
Melanocytic nevi & 59 & 5.8 \\
Alopecia areata & 57 & 5.6 \\
Acne & 57 & 5.6 \\
Nail disorders & 34 & 3.3 \\
Vascular malformations/hemangiomas & 30 & 3.0 \\
Psoriasis & 27 & 2.6 \\
Bacterial infections & 27 & 2.6 \\
Fungal infections & 25 & 2.4 \\
Mastocytosis & 23 & 2.2 \\
Infestations (other than scabies) & 21 & 2.0 \\
Cysts/tumors & 16 & 1.5 \\
Hair disorders (other than alopecia areata) & 15 & 1.5 \\
Urticaria & 13 & 1.3 \\
Lichenoid dermatoses & 13 & 1.3 \\
Scabies & 13 & 1.3 \\
Epidermal nevi & 10 & 1.0 \\
Morphea & 8 & 0.8 \\
Genodermatoses & 6 & 0.6 \\
Pityriasis rosea & 6 & 0.6 \\
Granulomas & 6 & 0.6 \\
Erythema multiforme & 5 & 0.5 \\
Juvenile xanthogranuloma & 4 & 0.4 \\
Granuloma annulare & 4 & 0.4 \\
Lichen sclerosus et atrophicus & 4 & 0.4 \\
Disorders of the mucous membranes & 3 & 0.3 \\
Miscellaneous & 11 & 1.1 \\
Total & 1020 & 100 \\
\hline
\end{tabular}

eczema (2.8\%), neurodermatitis (lichen simplex chronicus) $(0.6 \%)$, and photodermatitis $(0.3 \%)$. The incidence of $\mathrm{AD}$ decreased with increasing age, whereas the incidence of contact dermatitis and pityriasis alba showed an opposite trend. Seborrheic dermatitis affected both sexes equally and was most common within the first 4-6 weeks of life, followed by a rapid decline in incidence until puberty. Figure 1 depicts the percentile distribution of the dermatitis/eczema group.

Viral infections were found to be the second most common dermatosis having been diagnosed in $12.5 \%$ of the study population. Warts were seen in the majority of these cases (58.9\%), whereas the remainder was diagnosed with molloscum contagiosum (27\%) and viral exanthems (varicella, exanthema subitum, erythema infectiosum, herpes zoster, hand, foot, and mouth disease (HFMD), and Gianotti-Crosti syndrome). Molloscum contagiosum was predominantly seen in infants and preschoolers whereas the incidence of warts peaked in the scholar and teenage years (Figure 2). The incidence of HFMD and subsequent onychomadesis were $10.6 \%$. Two cases of Gianotti-Crosti syndrome associated with Epstein-Barr virus infection were diagnosed. 


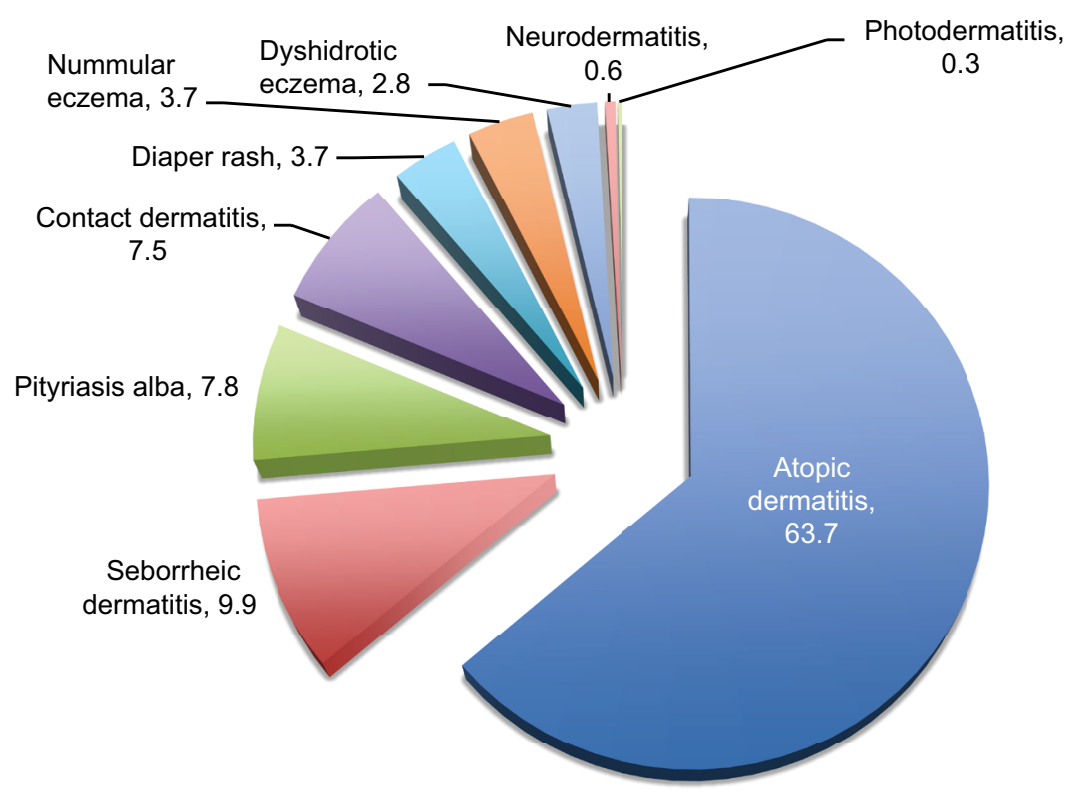

Figure I Distribution of dermatitis/eczema group (percentage).

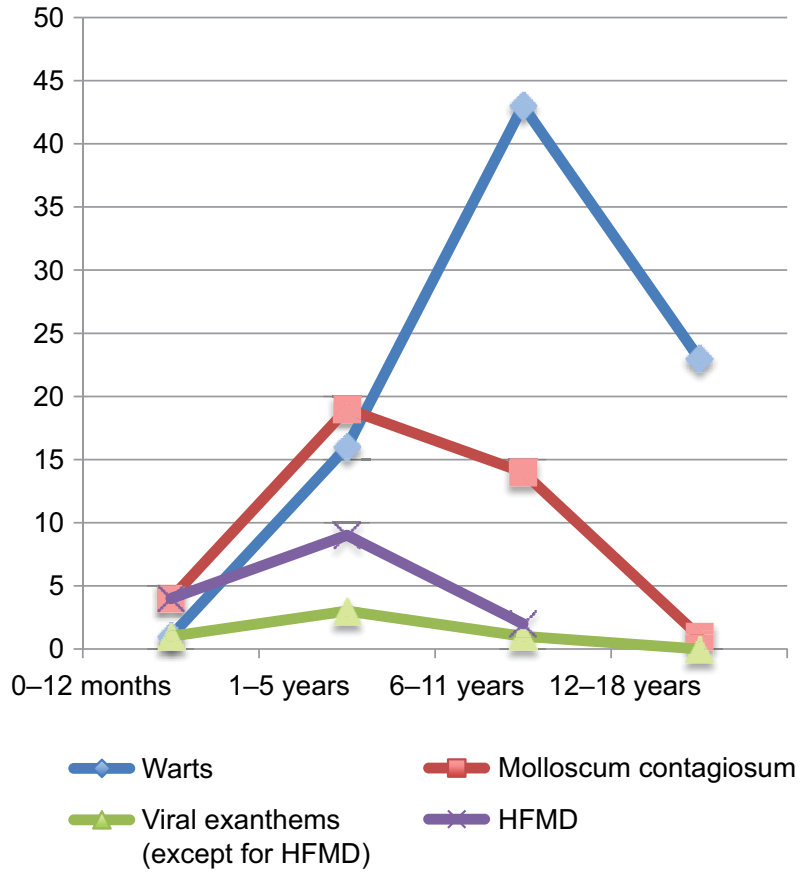

Figure 2 Types of viral infections by age group (number). Abbreviation: HFMD, hand, foot, and mouth disease.

Pigmentary disorders were the third most frequent diagnosis $(7.3 \%)$, followed by melanocytic nevi (5.8\%), alopecia areata (5.6\%), acne (5.6\%), nail disorders (3.3\%), and vascular malformations/hemangiomas (3.0\%). Of note, the incidence of mastocytosis in our study was $2.2 \%(\mathrm{n}=23)$. A femaleto-male sex ratio of 1.5 (14 vs 9) was found in the 23 cases analyzed. In $56.5 \%$ of the cases ( 13 of 23 ), the disease onset occurred after the age of 2 years. The clinical presentation was most commonly urticaria pigmentosa (52.2\%) (Figure 3), followed by solitary mastocytoma (47.8\%). No cases of diffuse cutaneous mastocytosis were observed. Family history for mastocytosis was reported in only 1 case. Darier's sign was positive in $91.3 \%$ of the cases. Skin biopsy for histologic confirmation was undertaken in 4 patients.

Lichenoid dermatoses were seen in fewer patients $(1.3 \%)$. In contrast to the adult population, lichen striatus $(n=5)$, lichen nitidus ( $\mathrm{n}=4)$, and Mucha-Habermann syndrome $(\mathrm{n}=3)$ were more common than lichen planus $(\mathrm{n}=1)$.

Genodermatoses were very rare in the study population $(0.6 \%)$ and were represented by ichthyosis vulgaris, diffuse palmoplantar keratoderma (Figure 3), lamellar ichthyosis, epidermolysis bullosa, and incontinentia pigmenti. Other rare diagnoses were Baboon syndrome, Gougerot-Carteaud

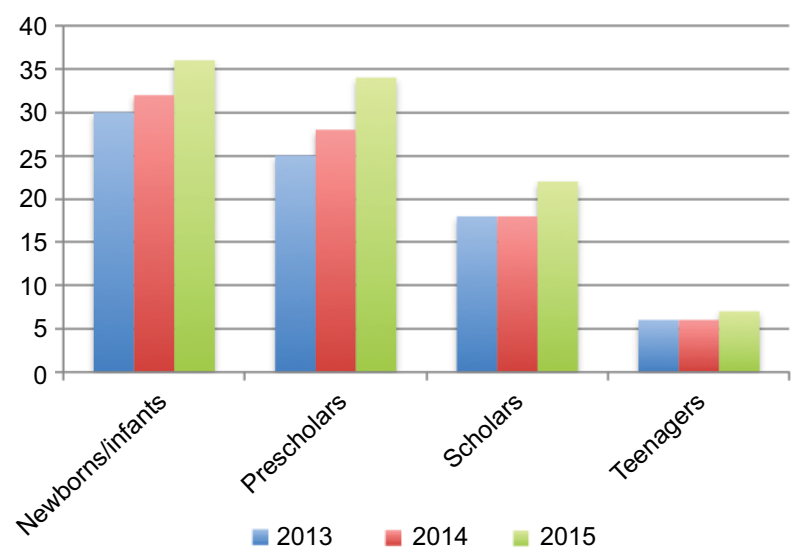

Figure 3 Atopic dermatitis over the study years in various age groups (percentage). 
syndrome, Sweet's syndrome, knuckle pads, blistering disorders, livedo reticularis, and a case of purpuric exanthem due to underlying sickle cell anemia. Table 2 presents the distribution of the dermatoses in the study population grouped by etiology.

\section{Discussion}

The results of this study are in accordance with some previous studies from Greece and other Western countries ${ }^{3-9}$ but differ from other studies. ${ }^{10-12}$ The variation in the incidence of certain skin diseases among studies may depend on the method of classification or may be due to differences between populations regarding genetic, socioeconomic, or environmental factors. ${ }^{7-9}$ For instance, the incidence of some common skin diseases, such as diaper dermatitis, was found to be relatively low but it is plausible to assume that such common skin disorders are frequently treated in the primary care setting or by other specialists, which in turn may result in the underestimation of their incidence in our study.

A female-to-male sex ratio of 1.1:1 was found in our study. This corresponds with the findings of some similar studies. ${ }^{5-11}$ The majority of the patients treated in our department are preschoolers and scholars $(39.8 \%$ and $38.9 \%$ respectively), while newborns and infants account for only $10.9 \%$ of the cases.

$\mathrm{AD}$ is a major public health problem worldwide ${ }^{6,710-14} \mathrm{It}$ is the most common skin disease in children and the leading reason for visiting a dermatologist in developed countries..$^{3-5}$ This was also depicted in our study. AD was the most frequent dermatosis among all age groups, found in $20.9 \%$ of the study population. It is more frequent in toddlers and preschoolers, decreasing gradually with increasing age. A slight increase, though not statistically significant, of the frequency over the study years was observed (Figure 4). Further studies following the prevalence rates of $\mathrm{AD}$ in our region over longer time periods should be performed.

Table 2 Skin diseases in the study population grouped after etiology/pathogenesis

\begin{tabular}{lll}
\hline Skin disease & $\mathbf{n}$ & $\%$ \\
\hline Inflammatory disorders & 575 & 56.4 \\
Infections & 179 & 17.5 \\
Disorders of skin appendages & 106 & 10.5 \\
Tumors & 79 & 7.7 \\
Infestations & 34 & 3.3 \\
Vascular malformations & 30 & 2.9 \\
Genodermatoses & 6 & 0.6 \\
Miscellaneous & 11 & 1.1 \\
Total & 1020 & 100 \\
\hline
\end{tabular}

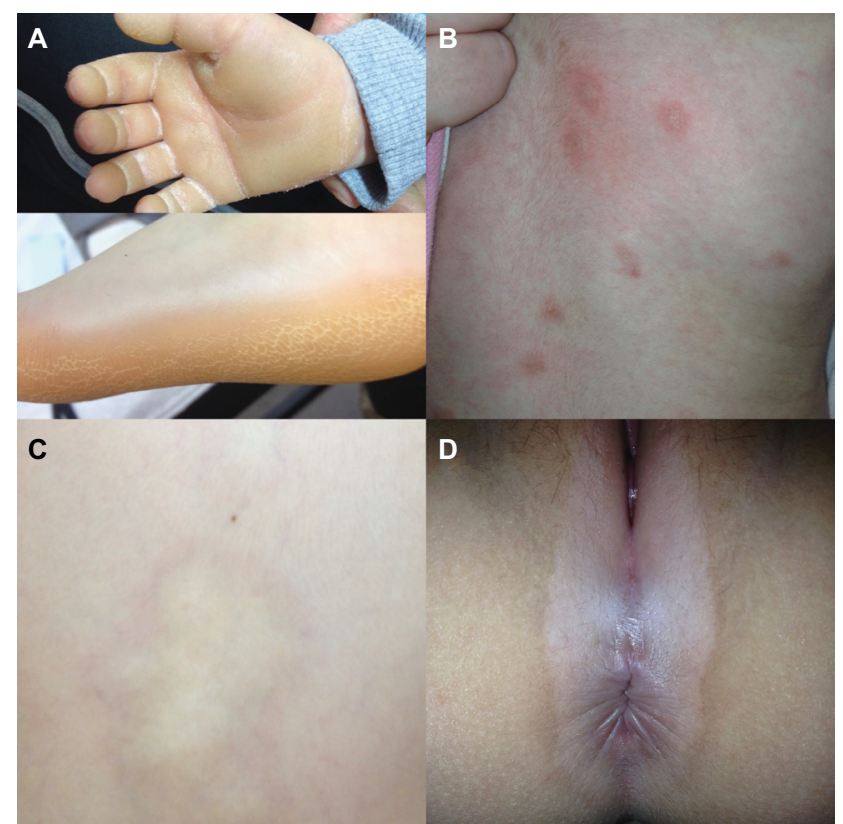

Figure 4 (A) Diffuse palmoplantar keratoderma: thick yellow-brown, well demarcated, parchment-like hyperkeratosis involving the palms and soles. (B) Uricaria pigmentosa: widespread reddish brown papules and urtication of some lesions upon trauma (Darier'sign). (C) Morphea: An atrophic hypopigmented patch with a diffuse rim of erythema. (D) Vitiligo: a well-demarcated patch of depigmentation around vulva and anus.

AD imposes an enormous burden on the personal, social, emotional, and financial resources of the patients and their families. Taking into consideration the increasing prevalence of $\mathrm{AD}$ in our region, development of special departments, educational programs, and group sessions ("eczema schools") devoted to improvement of care and prevention of atopic eczema should be started.

In developed countries, a significant increase in the prevalence of AD has been observed over the last decades, possible due to small family size, increased income and education, better socioeconomic status, improvement in sanitation, increased use of antibiotics, and the so-called "Western lifestyle" as well as earlier diagnosis. ${ }^{15-19}$ On the contrary, in developing countries, infections and infestations remain the most prevalent skin disease in the pediatric population, whereas $\mathrm{AD}$ is a rather rare entity. ${ }^{10}$

Not surprisingly, warts and molloscum contagiosum represent the most common viral infections in our study. ${ }^{3-4}$ Molloscum contagiosum is more prevalent in infants and preschoolers, whereas the peak age for warts is in the scholar and teenage years. An outbreak of HFMD was observed in our region during 2012-2013. ${ }^{20}$ This outbreak of HFMD, and of the associated onychomadesis, is confirmed in our study.

Pigmentary disorders account for $7.6 \%$ of the cases. The incidence rate of this diagnostic group, which included postinflammatory hyper- or hypo-pigmentation, hypochromic 
nevi, nevus anemicus, and vitiligo, may be attributed to the resemblance of certain disorders to vitiligo, which often causes significant stress to the parents and embarrassment to the child. Vitiligo was diagnosed only in $0.9 \%$ of the study population.

Melanocytic nevi, congenital and acquired, are a common reason for dermatologic consultation. This is confirmed by our study and various studies in Southern Europe., ${ }^{4,14}$ The improved education of the general population about the damaging effect of UV radiation in early life and the possible development of a melanoma in association with a pre-existing nevus may be a source of anxiety for the parent. Nevi - especially congenital - which are localized on areas of important esthetic value, may also constitute cause of cosmetic disturbance and impaired self-esteem.

In our region, the incidence of alopecia areata appears to be considerably higher than in Athens (5.6\% vs $2.4 \%$ ) and the incidence of psoriasis is slightly higher $(2.6 \% \mathrm{vs}$ $1.8 \%){ }^{4}$ The interpretation of these findings is difficult. The low incidence of acne in our study may be attributed to the fact that in Greece children and adolescents with acne are usually referred to private practitioners.

The high incidence of mastocytosis $(2.2 \%)$ in our study was surprising. No similar findings have been observed previously in our country. An epidemiologic study conducted between 1974 and 1976 in our department had reported only 8 cases of urticaria pigmentosa in a population of 12000 patients. The high incidence of mastocytosis in our study may be attributed to overdiagnosis, overestimation due to the relatively small study population, and the fact that our department is one of the few departments of pediatric dermatology in Northern Greece or it may represent the real incidence of mastocytosis in our region. Further investigations should focus on this subject.

The fact that solitary mastocytoma accounts for $47.8 \%$ of all cases of mastocytosis may be attributed to the open access to a pediatric dermatology department in the Greek public health system. The incidence of solitary mastocytoma may be underestimated in other studies conducted in countries where referral to dermatologists is required as this diagnosis requires a high degree of suspicion.

\section{Conclusion}

$\mathrm{AD}$ is the most significant childhood skin disorder in our region. Viral infections, pigmentary disorders, and melanocytic nevi account for a high proportion of the consultations. Of note is the high prevalence of mastocytosis observed in our study.

\section{Disclosure}

The authors report no conflicts of interest in this work.

\section{References}

1. Hayden GF. Skin diseases encountered in a pediatric clinic. A one-year prospective study. Am J Dis Child. 1985;139(1):36-38.

2. Williams HC. Epidemiology of skin disease. In: Champion RH, Burton JL, Burns DA, Breathnach SM, editors. Rook/Wilkinson/Ebling Textbook of Dermatology. Vol 1, 6th ed. Oxford: Blackwell Science; 1998:139-157.

3. Tunnessen WW Jr. A survey of skin disorders seen in pediatric general and dermatology clinics. Pediatr Dermatol. 1984;1(3):219-222.

4. Katsarou A, Armenaka M, Kosmadaki M, et al. Skin diseases in Greek and immigrant children in Athens. Int J Dermatol. 2012;51(2):173-177.

5. Wenk C, Itin PH. Epidemiology of pediatric dermatology and allergology in the region of Aargau, Switzerland. Pediatr Dermatol. 2003;20(6): 482-487.

6. Ruiz-Maldonado R, Tamayo Sánchez L, Velázquez E. Epidemiologia de las enfermedades de la piel en diez mil pacientes en edad pediatrica. [Epidemiology of skin diseases in 10,000 patients of pediatric age]. Bol Med Hosp Infant Mex. 1977;34(1):137-161. Spanish.

7. Katsarou-Katsari A, Koumantaki-Mathioudaki E, Kostakis P, Stratigos

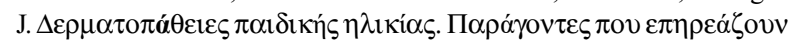
$\tau \eta \vee \varepsilon \pi i \pi \tau \omega \sigma \eta \tau 0 \nu \varsigma$. [Dermatoses of children and factors affecting their incidence]. Iatriki. 1990;57:149-155. Greek.

8. Inanir I, Şahin MT, Gündüz K, Dinç G, Türel A, Oztürkcan S. Prevalence of skin conditions in primary school children in Turkey: differences based on socioeconomic factors. Pediatr Dermatol. 2002;19(4):307-311.

9. Bottoni U, Dianzani C, Rossi ME, Carlesimo M, Calvieri S. Skin diseases in immigrants seen as outpatients in the Institute of Dermatology of the University of Rome "La Sapienza" from 1989 to 1994. Eur J Epidemiol. 1998;14(2):201-204.

10. WHO. Department of Child and Adolescent Health and Development. Epidemiology and Management of Common Skin Diseases in Children in Developing Countries; WHO/CAH 2005. Available from http://apps. who.int/iris/bitstream/10665/69229/1/WHO_FCH_CAH_05.12_eng. pdf. Accessed March 17, 2017.

11. Mohammedamin RS, van der Wouden JC, Koning S, et al. Increasing incidence of skin disorders in children? A comparison between 1987 and 2001. BMC Dermatol. 2006;6:4.

12. Nanda A, Al-Hasawi F, Alsaleh QA. A prospective survey of pediatric dermatology clinic patients in Kuwait: an analysis of 10,000 cases. Pediatr Dermatol. 1999;16(1):6-11.

13. Hon KL, Leung TF, Wong Y, Ma KC, Fok TF. Skin diseases in Chinese children at a pediatric dermatology center. Pediatr Dermatol. 2004;21(2):109-112.

14. Casanova JM, Sanmartín V, Soria X, Baradad M, Martí RM, Font A. Dermatologia de un hospital general universitario en Espana. [Childhood dermatosis in a dermatology clinic of a general university hospital in Spain]. Actas Dermosifiliogr. 2008;99(2):111-118. Spanish.

15. Williams HC. Is the prevalence of atopic dermatitis increasing? Clin Exp Dermatol. 1992;17(6): 385-391.

16. Sturgill S, Bernard LA. Atopic dermatitis update. Curr Opin Pediatr. 2004;16(4):396-401.

17. Williams HC. Epidemiology of atopic dermatitis. Clin Exp Dermatol. 2000;25(7):522-529.

18. Marks R, Kilkenny M, Plunkett A, Merlin K. The prevalence of common skin conditions in Australian school students: 2. Atopic dermatitis. $\mathrm{Br}$ J Dermatol. 1999;140(3):468-473.

19. Williams HC, Strachan DP, Hay RJ. Childhood eczema: disease of the advantaged? BMJ. 1994;308(6937):1132-1135.

20. Apalla Z, Sotiriou E, Pikou O, et al. Onychomadesis after hand-footand-mouth disease outbreak in Northern Greece: case series and brief review of the literature. Int J Dermatol. 2015;54(9):1039-1044. 


\section{Publish your work in this journal}

Clinical, Cosmetic and Investigational Dermatology is an international, peer-reviewed, open access, online journal that focuses on the latest clinical and experimental research in all aspects of skin disease and cosmetic interventions. This journal is included on PubMed. The manuscript management system is completely online and includes a very quick and fair peer-review system, which is all easy to use. Visit http://www.dovepress.com/testimonials.php to read real quotes from published authors 